BMJ Nutrition,

Prevention \& Health

\title{
Randomised double-blind placebo- controlled intervention study on the nutritional efficacy of a food for special medical purposes (FSMP) and a dietary supplement in reducing the symptoms of veisalgia
}

\author{
Bernhard Lieb, Patrick Schmitt
}

To cite: Lieb B, Schmitt P. Randomised double-blind placebo-controlled intervention study on the nutritional efficacy of a food for special medical purposes (FSMP) and a dietary supplement in reducing the symptoms of veisalgia. BMJ Nutrition, Prevention \& Health 2020;3:e000042. doi:10.1136/ bmjnph-2019-000042

- Additional material is published online only. To view please visit the journal online (http://dx.doi.org/10.1136/ bmjnph-2019-000042).

Institute of Molecular Physiology (imP), Johannes GutenbergUniversity (JGU), Mainz, Germany

\section{Correspondence to}

Professor Bernhard Lieb, Institute of Molecular Physiology, Johannes Gutenberg-University (JGU), Mainz 55128, Germany; lieb@uni-mainz.de

Received 28 June 2019 Revised 28 February 2020 Accepted 7 March 2020 Published Online First 30 April 2020

\section{Check for updates}

(c) Author(s) (or their employer(s)) 2020. Re-use permitted under CC BY-NC. No commercial re-use. See rights and permissions. Published by BMJ.

\section{ABSTRACT}

Objective To assess whether the symptoms of veisalgia can be reduced by intense water supply and the intake of antioxidative supplements and plant extracts.

Methods We performed the world's largest randomised double-blind placebo-controlled intervention study (214 participants) on the efficacy of a food for special medical purposes (FSMP) against veisalgia symptoms. We analysed the effectiveness of: (1) an FSMP, including distinct plant extracts, vitamins and minerals, and additional (antioxidative) compounds; (2) a dietary supplement only comprising vitamins and minerals and additional (antioxidative) compounds; and (3) a placebo containing only glucose. The study followed the CONSORT (Consolidated Standards of Reporting Trials) guidelines and trial registration was not necessary.

Results Our study showed no statistically significant relationship between the variation of body water content and alcohol consumption. Contrary to common belief, the results showed that intervention with a supplement containing vitamins and minerals and additional antioxidative compounds did not lead to a statistically significant improvement in hangover symptoms. Additionally, our results confirmed a high individual variability in developing hangover symptoms depending on the amount of alcohol. Thus, standardisation of the amount of alcohol consumed in hangover studies does not necessarily contribute to the validity of the results. Finally, this study found a number of positive effects on certain hangover symptoms as a result of the FSMP, which were most likely due to the plant extracts contained within the food.

Conclusion This study significantly supports the finding that haemostasis of electrolytes and minerals caused by alcohol consumption might be negligible and that no significant dehydration due to alcohol consumption seems to occur. Additionally, only the FSMP provides evidence for a significant efficiency in the reduction of hangover symptoms such as headache and nausea following moderate and non-excessive alcohol consumption.

\section{What this paper adds?}

- Complex mixtures of nutritional food supplements seem suitable for effective treatment of veisalgia in the context of non-excessive alcohol consumption.

- Haemostasis of electrolytes and minerals inferred by alcohol consumption might be neglectable.

- No significant dehydration due to alcohol consumption seems to occur after moderate alcohol consumption.

\section{INTRODUCTION}

Veisalgia refers to all disorders resulting from the consumption of alcohol. It comprises all physical and psychological symptoms perceived on the day after one-time use of alcohol when the blood alcohol concentration is $0 \% .^{1}$ The intensity of symptoms increases while metabolic alcohol degradation progresses, culminating at $0 \%$ blood alcohol, ${ }^{2}$ and may persist for up to 24 hours. ${ }^{3}$ The symptoms are caused directly by the alcohol itself, possible congeners, and metabolic intermediates. ${ }^{4}$ According to Penning the most frequent impairments are exhaustion $(95.5 \%)$, thirst $(89.1 \%)$, fatigue $(88.3 \%)$, headaches $(87.7 \%)$, dry mouth $(83 \%)$ and nausea $(81.4 \%)$, and do not necessarily occur in a linear relationship with the amount of alcohol consumption. ${ }^{5}$ Various additional factors also play a decisive role in veisalgic diathesis. Thus, intra-individual genderindependent variations in the intensity and frequency of the perceived impairments occur independent of the amount of alcohol consumed. ${ }^{67}$ Dehydration and the concomitant loss of electrolytes is often cited in the literature as causing symptoms such as thirst and headache, but according to Ylikahri et 


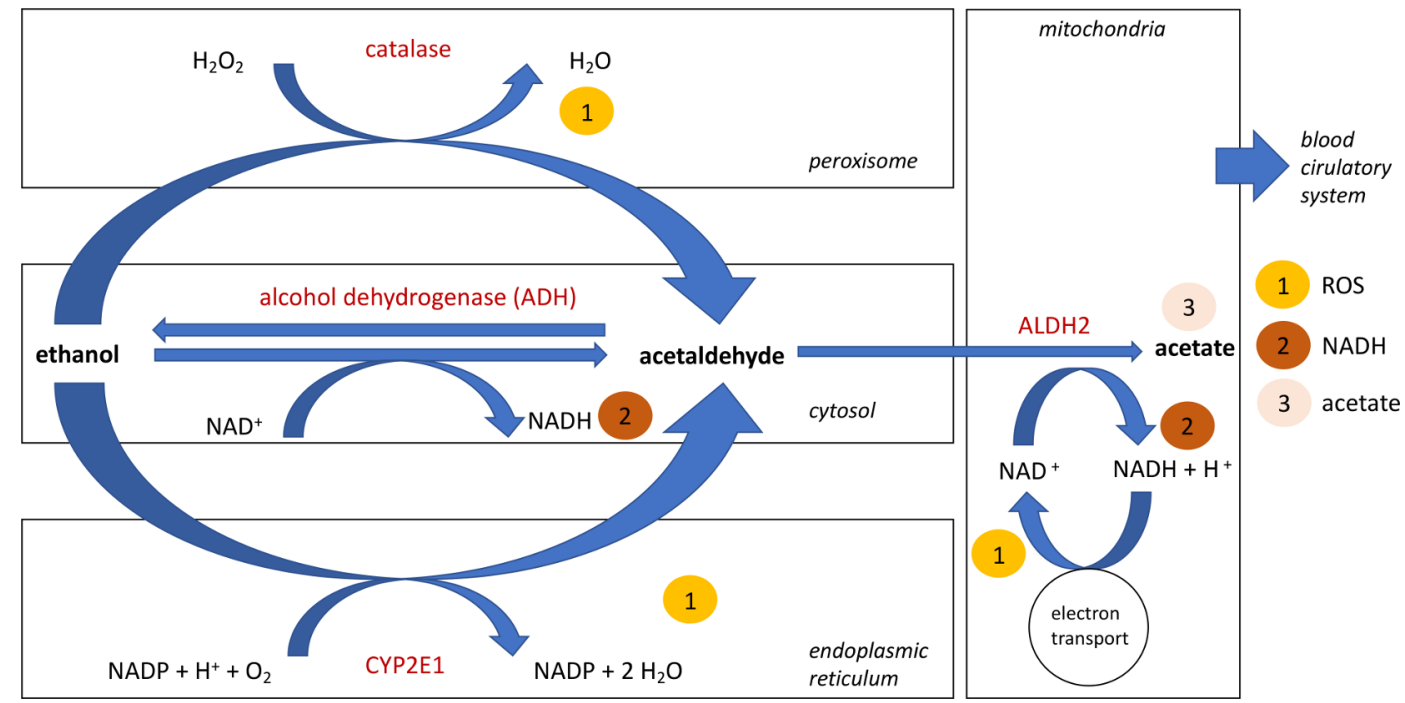

Figure 1 Oxidative pathways of alcohol metabolism. Alcohol is mainly converted into acetaldehyde in the cytosol by the enzyme alcohol dehydrogenase (ADH). CYP2E1 is involved in the conversion of ethanol to acetaldehyde in the endoplasmic reticulum when higher concentrations of alcohol are present. The conversion of ethanol to acetaldehyde takes place in the peroxisome via the enzyme catalase. Acetaldehyde is converted into acetate in the mitochondria by the enzyme aldehyde dehydrogenase-2 (ALDH2). The conversion of ethanol by the enzyme catalase and CYP2E1 as well as the oxidation of NADH lead to the formation of free oxygen radicals. The final products of alcohol metabolism are free oxygen radicals (ROS) (1), changes in NADH levels (2) and acetate (3). This figure is modelled after Zakhari ${ }^{13}$ and Zimatkin et al. ${ }^{14}$

al no significant changes in electrolyte balance could be detected after alcohol consumption. ${ }^{8}$

The absorption of ethanol takes place via diffusion in the stomach, the duodenum and the distal sections of the intestine. In the duodenum or jejunum, complete ethanol uptake occurs within approximately 2 hours. ${ }^{9}$ Immediately after resorption, ethanol diffuses into tissues that have high blood supply requirements, such as the brain. Ethanol is an amphipathic solution with an oilwater distribution ratio of 1:30. Thus, ethanol is mainly distributed by the blood and the lymphatic system. ${ }^{9}$ The "first pass metabolism" pathway of ethanol encompasses all metabolic processes during resorption by the upper gastrointestinal tract or liver before the ethanol reaches the blood circulation system. In men about $9.1 \%$, and in women about $8.4 \%$, of the amount of alcohol consumed is metabolised via this pathway (figure 1). Ethanol is oxidised to acetaldehyde by the enzyme alcohol dehydrogenase $(\mathrm{ADH})$ in the endothelia of the stomach. ${ }^{9}$ Different $\mathrm{ADH}$-isoforms lead to inter-individual differences in the effectiveness of this pathway, and the capacity appears to be greater in the liver than in the stomach. ${ }^{10}$ This seems to decrease in efficiency with increasing age. ${ }^{11}$ After this process, the intracellular enzymatically regulated decay of alcohol mainly occurs within the liver. Ethanol is oxidised to the intermediate acetaldehyde by $\mathrm{ADH}$, which is a reversible process but not substrate inducible. $\mathrm{ADH}$ converts approximately $100 \mathrm{mg}$ of ethanol $/ \mathrm{kg}$ body weight and thus correlates to a mean ethanol conversion rate of 6-9 g/hour. ${ }^{9}$ The cerebrum mainly "uses" the enzyme catalase, which is localised within peroxisomes and results in the production of acetaldehyde. ${ }^{12}$ In addition to the conversion of ethanol by $\mathrm{ADH}$ and catalase, other oxidases are involved within a second degradation pathway: the microsomal ethanol oxidising system (MEOS). Cytochrome P450 isoenzymes-in particular, CYP2E1, 1A2, and 3A4-contribute to ethanol metabolism in the endoplasmic reticulum of cerebral and hepatic tissues. The conversion of ethanol to acetaldehyde by CYP2E1 (figure 1) leads to the formation of free oxygen radicals-also known as reactive oxygen species (ROS) such as hydroxyethyl, superoxide anions and hydroxyl radicals. ${ }^{913}$ Thus, the decay of ethanol within the cerebral tissue appears to be performed mainly by the two enzymes catalase and CYP2E $1 .{ }^{14}$ Acetaldehyde is further oxidised by aldehyde dehydrogenase-2 (ALDH2, figure 1) in mitochondria, ultimately creating acetate. ${ }^{912} 14$ Acetaldehyde is also able to directly induce the formation of ROS by activating the NADPH oxidase NOX2, resulting in apoptosis-inducing cell membrane damage. ${ }^{15}$ Additionally, CYP2E1 expressed within the brain leads to the formation of ROS-for example, 1-hydroxyethyl radical and hydrogen peroxide, the hydroxyl radical, and the superoxide anion-during ethanol degradation. ${ }^{9}$ The reduction of $\mathrm{NAD}^{+}$associated with $\mathrm{ADH}$ (figure 1) can lead to pathological concentrations of ROS in the hepatic tissue. ${ }^{16}$ Thus, the final products of alcohol metabolism are acetate, varying concentrations of $\mathrm{NADH} / \mathrm{H}^{+}$, and ROS.

Antioxidant enzymes may play a key role in eliminating and neutralising ROS. The one-time consumption of alcohol seems to significantly reduce the concentration of antioxidants in skin. ${ }^{17}$ In general, ethanol induces the inhibition of superoxide dismutase activity in the blood plasma and hepatic tissue, resulting in less efficient elimination of ROS and, subsequently, causing oxidative 
stress in the hepatic tissue. ${ }^{18}$ This oxidative stress may be increased by further ethanol-induced factors and processes: (1) the oxidative inhibition of catalase activity in the liver and brain, resulting in an accumulation of $\mathrm{H}_{2} \mathrm{O}_{2}{ }^{1920}$; (2) the induction of the hepatic enzymes glutathione peroxidase and glutathione reductase; and (3) the formation of free oxygen radicals, leading to mitochondrial dysfunction in cerebral tissue. ${ }^{21}$ Thus, oxidative stress induced by ethanol consumption seems to be an important factor causing hangover symptoms. Congeners like phenols, aldehydes, fusel alcohols, tannins and meth$\mathrm{anol}^{6}$ are also believed to cause hangover symptoms. ${ }^{42}$ However, the overall contribution of congeners to hangover symptoms is significantly lower than that of the ethanol itself. ${ }^{23}$

Acute hangover symptoms are mainly treated by different synthetic drugs, for example, acetylsalicylic acid or ibuprofen, but many nutritional substances are also used for prophylactically avoiding hangover symptoms. ${ }^{24}$ The latter have been tested and evaluated by various intervention studies. However, the validity of those intervention studies is often questioned due to the subjectively obtained quantitative and qualitative recordings of the intensity of perceived hangover symptoms. The combined analyses of the Acute Hangover Scale (AHS) and the Hangover Symptoms Scale (HSS) ${ }^{725}$ allow for standardised implementation in hangover intervention studies. The HSS is primarily suitable for surveys, while the AHS is more suitable for intervention studies. ${ }^{2}$ The methodological quality of intervention studies is reflected in part by a Jadad score, which is often used to evaluate clinical trials. ${ }^{2426}$ While several natural products have been recommended for hangover treatment by diverse studies, there is no strong scientific evidence on their concrete intervention success in humans. Some studies have shown some effects, the number of participants were very low ( $<30$ participants), placebos were not implemented, or the results were not confirmed by any statistical significance. In consequence, several studies achieved only a low Jadad index, the implications of which have been critically discussed..$^{827} 28$

We present here the first and probably world's largest three-way, double-blind, randomised, placebo-controlled intervention trial on the nutritional efficacy of a food for special medical purposes (FSMP) in veisalgia. The main objective of this study was to evaluate whether the use of an FSMP has a significant effect on the severity of 47 hangover-associated disorders symptoms. We also wanted to analyse to what extent the plant extracts implemented in the FSMP may contribute to the alleviation of symptoms, hypothesising that most probably only the FSMP would be most efficient.

Lastly, we hypothesised a correlation between the severity of hangover symptoms in general and the amounts of alcohol consumed due to congeners included in certain beverages and fluid loss due to alcohol consumption, which has frequently been described in the literature .
Table 1 Qualitative composition of the interventions: the dietary supplement, the administered vitamins and minerals solution, and the placebo

\begin{tabular}{|c|c|c|c|}
\hline & $\begin{array}{l}\text { Dietary } \\
\text { supplement }\end{array}$ & $\begin{array}{l}\text { Vitamins and } \\
\text { minerals }\end{array}$ & Placebo \\
\hline \multirow[t]{5}{*}{$\begin{array}{l}\text { Plant } \\
\text { extracts }\end{array}$} & $\begin{array}{l}\text { Fruit extract } \\
\text { (Malpighia } \\
\text { glabra) }\end{array}$ & & \\
\hline & $\begin{array}{l}\text { Fruit extracts } \\
\text { (Opuntia ficus } \\
\text { indica) }\end{array}$ & & \\
\hline & $\begin{array}{l}\text { Leaf extract } \\
\text { (Ginkgo biloba) }\end{array}$ & & \\
\hline & $\begin{array}{l}\text { Leaf extract } \\
\text { (Salix alba) }\end{array}$ & & \\
\hline & $\begin{array}{l}\text { Root extract } \\
\text { (Zingiber } \\
\text { officinale) }\end{array}$ & & \\
\hline \multirow[t]{7}{*}{$\begin{array}{l}\text { Vitamins and } \\
\text { minerals }\end{array}$} & $\begin{array}{l}\text { Magnesium } \\
\text { citrate }\end{array}$ & $\begin{array}{l}\text { Magnesium } \\
\text { citrate }\end{array}$ & \\
\hline & $\begin{array}{l}\text { Potassium } \\
\text { chloride }\end{array}$ & $\begin{array}{l}\text { Potassium } \\
\text { chloride }\end{array}$ & \\
\hline & $\begin{array}{l}\text { Sodium } \\
\text { bicarbonate }\end{array}$ & $\begin{array}{l}\text { Sodium } \\
\text { bicarbonate }\end{array}$ & \\
\hline & Zinc citrate & Zinc citrate & \\
\hline & Riboflavin & Riboflavin & \\
\hline & $\begin{array}{l}\text { Thiamine } \\
\text { hydrochloride }\end{array}$ & $\begin{array}{l}\text { Thiamine } \\
\text { hydrochloride }\end{array}$ & \\
\hline & Folic acid & Folic acid & \\
\hline \multirow[t]{4}{*}{$\begin{array}{l}\text { Additional } \\
\text { compounds }\end{array}$} & $\begin{array}{l}\text { Steviol } \\
\text { glycosides }\end{array}$ & $\begin{array}{l}\text { Steviol } \\
\text { glycosides }\end{array}$ & \\
\hline & Inulin & Inulin & \\
\hline & Glucose & Glucose & Glucose \\
\hline & Flavour & Flavour & Flavour \\
\hline
\end{tabular}

The complete FSMP includes all components, whereas the second intervention omits plant extracts and the placebo solely contains sugar. Additional compounds are only relevant to taste. Each composition contained $7.5 \mathrm{~g}$ of powder which was dissolved in $100 \mathrm{~mL}$ of water.

FSMP, food for special medical purposes.

\section{METHODS}

The double-blind study recruited 214 healthy adult men and women aged 18-65 years. People with chronic diseases or allergies, using any kind of drugs, being or planning to become pregnant within the next 6 months, taking regular medication, or reporting as alcoholics were excluded. Premixed solutions were handed out $45 \mathrm{~min}$ before and immediately after the participants drank alcohol. The solutions contained $7.5 \mathrm{~g}$ of powder dissolved in $100 \mathrm{~mL}$ of water (table 1). All solutions were manufactured and bottled by Fermenta GmbH. Two interventions and one placebo group were tested. Intervention group 1 received the FSMP, consisting of glucose, vitamins, minerals and plant extracts. Intervention group 


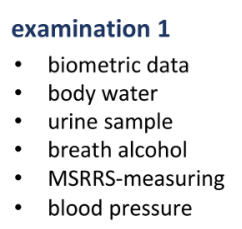

examination 1

- biometric data

- body wate

- MSRRS-measuring

- blood pressure examination 2

- biometric data

- body water

- urine sample

- breath alcohol

- MSRRS-measuring

- blood pressure examination 3

- biometric data

- body water

- urine sample

- breath alcohol

- MSRRS-measuring

- blood pressure

- questionnaire for the assessment of hangovereffects

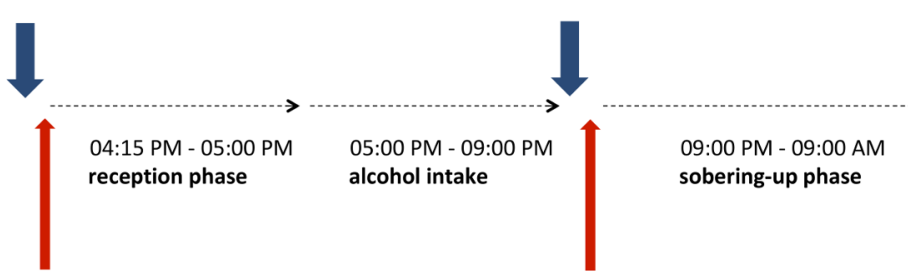

intervention application

intervention application

Figure 2 Timeline of the study. The study was divided into an initiating phase (45 min), a 4 hour consumption phase, and a 12 hour sobering phase. A total of three examination times were set: before the admission phase, after the consumption phase, and after the sobering phase. The interventional treatments were performed after the first examination before the admission phase and after the end of the consumption phase. MSRRS, multiple spatially resolved reflection spectroscopy.

2 received a dietary supplement which consisted of the FSMP contents minus the plant extracts of the FSMP. The placebo exclusively contained an aromatised glucose solution. All interventions were flavoured and optically blinded with food colouring.

Randomization was performed by the software Randlist from datinf GmbH according to Schulz et al for 300 participants. ${ }^{29}$ The random generator used was based on the algorithm of Park and Miller with a Bays-Durham correction, and the randomisation (seed: 2024107392) complied with the consort guidelines. ${ }^{30}$

Beverages provided were "standard" beer $(4.8 \%$ alcohol), mixed beer (Radler; $2.5 \%$ alcohol), white wine (11\% alcohol), and white wine spritzer (50\% sparkling water, $50 \%$ wine; $5.5 \%$ alcohol). Each participant was free to choose. The participants were not allowed to consume alcohol before or after the experiment. The amount of alcohol consumed during the study was up to each participant (see online supplementary file), but participants were observed to avoid any excessive misuse. The participants had to be sober at the beginning of the study and were not allowed to consume further alcohol after the first phase. Small meals were allowed during phase 1. Smoking outside the laboratory was permitted, but was documented and is reflected within the results. All participants were allowed to drop out at any time. The study was carried out in a constantly illuminated room, comfortably air-conditioned at $20^{\circ} \mathrm{C}$. The distinct phases of the study are described in figure 2: (1) first measurement, (2) consumption, (3) sobering up, and (4) second measurement phase. All anthropometric characteristics measured and calculated are listed in table 2 .

All participants were tested for alcohol consumption before the experiment by performing a breath alcohol test (Alcofind DA-8000). Urine and vital parameters of all participants were examined using AtlasHome urine test strips. The concentrations of glucose, ketone, proteins, blood, nitrite and leucocytes were measured, as well as the $\mathrm{pH}$ value and the specific mass. The type and number of alcoholic and non-alcoholic drinks consumed by each person as well as their restroom-visiting frequencies were documented. After 4 hours, the previous measurements were taken again and the second interventions were given. All participants were advised to go home, sleep, and return

Table 2 Anthropometric comparison of the intervention groups

\begin{tabular}{|c|c|c|c|}
\hline & $\begin{array}{l}\text { FSMP } \\
(\mathbf{n}=69)\end{array}$ & $\begin{array}{l}\text { Vitamins and minerals } \\
(\mathbf{n}=76)\end{array}$ & $\begin{array}{l}\text { Placebo } \\
(\mathbf{n}=69)\end{array}$ \\
\hline Male (\%) & 65 & 53 & 50 \\
\hline Mean age (years) & $25.98 \pm 6.73$ & $25.59 \pm 8.51$ & $24.52 \pm 5.78$ \\
\hline Average body mass index $\left(\mathrm{kg} / \mathrm{m}^{2}\right)$ & $24.38 \pm 3.42$ & $23.90 \pm 2.70$ & $23.96 \pm 3.47$ \\
\hline Average body water (\%) & $53 \pm 0.04$ & $53 \pm 0.06$ & $52 \pm 0.05$ \\
\hline Average body fat (\%) & $23 \pm 0.07$ & $23 \pm 0.07$ & $23 \pm 0.07$ \\
\hline Average body musculature (\%) & $40 \pm 0.04$ & $39 \pm 0.04$ & $39 \pm 0.04$ \\
\hline
\end{tabular}

Anthropometric parameters including gender, age and body mass index $\left(\mathrm{kg} / \mathrm{m}^{2}\right)$ are shown. Additionally, fat, muscle and body water contents of participants ( $n=$ number) are shown as percentages and mean values, respectively. Standard deviations are indicated as well. FSMP, food for special medical purposes. 
back to the laboratory for a third follow-up examination at 9:00 am the next day. In order to exclude unauthorised alcohol consumption during the night and to ensure that the volunteers' blood alcohol concentrations were at $0 \%$, breath alcohol concentration was measured when the volunteers returned the next morning. The determined alcohol concentrations were compared with theoretical values calculated on the basis of the amount of alcohol consumed and the biometric data obtained according to the Widmark formula ${ }^{31}$ Additionally, the participants were asked to answer a standardised questionnaire to record the type and intensity of their perceived hangover symptoms. The qualitative assessment of the individually experienced 47 hangover symptoms was done according to the classification systems of Penning et $a l^{5}{ }^{5}$ The symptoms were evaluated using a scale of $0-10$ points $(0=$ no complaints, $10=$ severe). An extended AHS (see below) was calculated for each participant as a sum of each individual statement. The $p$ values were calculated for all groups and parameters by a two-sample heteroskedastic t-test.

In order to calculate the oxidative capacity of the interventions and the congeners of drinks provided, the ORAC (oxygen radical absorbance capacity) values were determined by SGS Fresenius GmbH. The water content of the participants was determined before the start of the test, after the consumption phase and during the follow-up examination after the sobering phase. The water content was determined with an analytical balance and calculated according to standard mathematical formulas. The antioxidative capacity of the skin tissue was determined by multiple spatially resolved reflection spectroscopy using a medically validated hand scanner from Biozoom Services $\mathrm{GmbH} .{ }^{17}$ The sevenfold measurements were carried out on the Thenar. The antioxidative capacity of the skin tissue was expressed during the measurement in standardised sizes from 0 (low) to 12 (high). The experimentally determined standard deviations were calculated (SD 0.0127 ). All measurements were carried out on a balance with a constant pressure of 7.85 Newtons. The change in the antioxidative capacity was determined by dividing the antioxidative capacity of the skin tissue determined before the start of the experiment by the antioxidative capacity of the skin tissue determined during the follow-up examination the next morning. The resulting value was compared with the amount of alcohol consumed using linear regression.

\section{RESULTS}

The study was performed as a double-blind placebocontrolled randomised crossover assay. We tested three different compounds: (1) a complete FSMP mixture; (2) an incomplete FSMP mixture (dietary supplement with vitamins and minerals but without plant extracts); and (3) a placebo (glucose). The proportions of male and female participants and other data such as mean values of age, body weight and body mass index are shown in table 2 .
The mean values of all parameters measured were nearly equal between all the groups. The FSMP intervention group consumed an average of $1.54 \mathrm{~g}$ of alcohol/ $\mathrm{kg}$ body weight. The average alcohol consumption rate was $0.62 \mathrm{~mL}$ of alcohol $/ \mathrm{min}$. The vitamin and mineral group consumed an average of $1.57 \mathrm{~g}$ of alcohol $/ \mathrm{kg}$ body weight. The average alcohol consumption rate was 0.62 $\mathrm{mL} / \mathrm{min}$. The placebo group consumed an average of $1.63 \mathrm{~g}$ of alcohol $/ \mathrm{kg}$ body weight. The average alcohol consumption rate was $0.62 \mathrm{~mL}$ of alcohol $/ \mathrm{min}$. Of the participants, $22 \%$ smoked and $26 \%$ had a meal during the evening (see online supplementary table 2). For the 47 reported symptoms, the mean values, standard deviations and statistical significance of total intensity (extended AHS total score) scores for all three intervention groups were calculated and compared with each other (table 3).

With regard to the detected intensities of the hangover symptoms, the extended AHS total scores were calculated. However, the respective error rates were very high, and thus no significant conclusions could be drawn. However, the calculated mean intensity levels of some specific symptoms revealed significant results. The headache intensity of the FSMP group had a mean value of 1.99, whereas the headache intensity for the placebo group was 2.97. Thus, the average headache intensity was reduced by $34 \%$ (FSMP 1.99, vitamins and minerals 2.34, placebo 2.97), showing a p value of 0.033 . In contrast, the vitamins and minerals group did not show any statistically significant effect on reducing headache intensity. Within the FSMP group, a mean intensity of 1.17 was observed for nausea. The placebo group showed a mean intensity for nausea of 2.03. Thus, the use of the FSMP resulted in an average nausea reduction of $42 \%$ (FSMP 1.17, vitamins and minerals 2.62, placebo 2.03) compared with the placebo group, with a $\mathrm{p}$ value of 0.036 . This pain reduction might be regarded as statistically significant in some way, although for the dietary supplement group there was no statistically significant reduction in nausea compared with the placebo group. In the case of the vitamin and mineral group, however, there was no statistically significant reduction in nausea compared with the placebo group. Furthermore, the FSMP group showed statistically significant reductions in the mean intensities of indifference ( $p$ value 0.037 ) and restlessness ( $p$ value 0.027 ) compared with the placebo group (for absolute values see table 3). The mean intensity of indifference was reduced by $27 \%$ to 2.59 (vitamins and minerals 3.37 , placebo 2.82 ), and the mean intensity of restlessness by $41 \%$ to 1.04 compared with the placebo group (vitamins and minerals 1.55 , placebo 1.76 ). The vitamins and minerals groups, again, showed no statistically significant reductions in symptoms. All other symptoms did not show any significant differences or reductions.

The quantitative analysis referring to the effect strength/quality of the intervention showed that the FSMP group reported a mean effectiveness value of 4.22 and the vitamins and minerals group reported a value of 
Table 3 Extended Acute Hangover Scale for all analysed symptoms

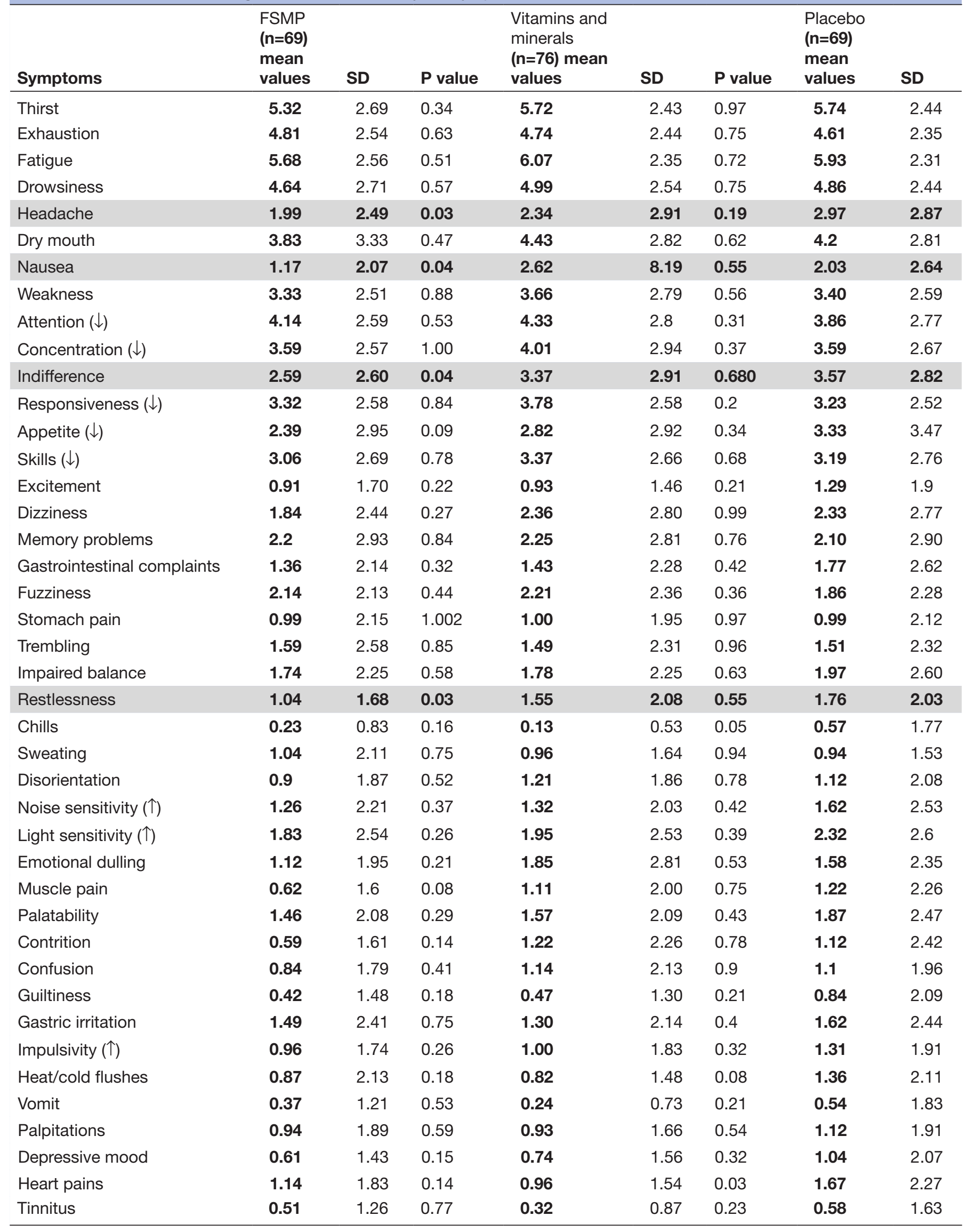


Table 3 Continued

\begin{tabular}{|c|c|c|c|c|c|c|c|c|}
\hline Symptoms & $\begin{array}{l}\text { FSMP } \\
(n=69) \\
\text { mean } \\
\text { values }\end{array}$ & SD & $P$ value & $\begin{array}{l}\text { Vitamins and } \\
\text { minerals } \\
(\mathrm{n}=76) \text { mean } \\
\text { values }\end{array}$ & SD & $P$ value & $\begin{array}{l}\text { Placebo } \\
(\mathbf{n}=69) \\
\text { mean } \\
\text { values }\end{array}$ & SD \\
\hline Nystagmus & 0.56 & 1.50 & 0.92 & 0.67 & 1.34 & 0.53 & 0.54 & 1.23 \\
\hline Irritability & 1.29 & 2.18 & 0.27 & 1.26 & 2.11 & 0.22 & 1.71 & 2.25 \\
\hline Breathing problems & 0.59 & 1.47 & 0.62 & 0.72 & 1.88 & 0.35 & 0.48 & 1.26 \\
\hline Anxiety & 0.17 & 0.98 & 0.86 & 0.29 & 1.14 & 0.41 & 0.14 & 0.97 \\
\hline Suicidal thoughts & 0.01 & 0.12 & 0.32 & 0.09 & 0.60 & 0.66 & 0.06 & 0.34 \\
\hline AHS total score & 83.38 & 55.53 & 0.21 & 92.08 & 57.54 & 0.76 & 96.36 & 64.63 \\
\hline
\end{tabular}

The mean values of the intensities from 0 (no complaints) to 10 (extreme complaints) of 47 hangover symptoms and the extended AHS total scores with the respective standard deviations (SD) and the statistical significances (P value) of all three intervention groups are given. Conspicious/significant parameters are highlighted in grey; $(\downarrow)$ indicates decrease $(d)$, and $(\uparrow)$ indicates increase(d).

AHS, Acute Hangover Scale; FSMP, food for special medical purposes.

2.67. The placebo group reported a mean effect value of 3.10 (table 4).

Thus, the mean perceived effect strength of the FSMP intervention was $36 \%$ higher than that of the placebo group ( $p=0.024)$ and $14 \%$ smaller in the vitamins and minerals group $(p=0.34)$. Only the first result with a $p$ value of 0.02 can be regarded as statistically significant. In order to evaluate whether a significant dehydration process could be observed and whether this process might be correlated with the amount of alcohol consumed, the relative changes in water content and the antioxidant capacity of the skin tissue were examined (see Methods). Both parameters were determined before and after the consumption phase and on day 2. All three intervention groups did not show any statistically significant correlation in either the relative amount of water or the antioxidative capacity in the skin tissue (table 5).

Additionally, we analysed the body water, the antioxidative capacity of the skin, the amounts of congeners, and the intensity of and distinct hangover symptoms, respectively, and the distribution of ethanol within the body fluids in accordance with the consumed proportion of alcohol. Further on, the dose-response dependency

Table 4 Assessment of the effect inferred by the participants: did the participants feel an effect by the interventions taken?

\begin{tabular}{lll}
\hline & $\begin{array}{l}\text { Mean } \pm \text { SD } \\
\text { effectiveness (0-10) }\end{array}$ & P value \\
\hline FSMP $(n=69)$ & $4.22 \pm 1.485$ & 0.02 \\
Vitamins and minerals $(n=76)$ & $2.67 \pm 1.30$ & 0.34 \\
Placebo $(n=69)$ & $3.10 \pm 1.365$ & - \\
\hline
\end{tabular}

The intervention groups were asked how much they observed the perceived effects of the received intervention on a scale from 0 (no effect) to 10 (extremely strong effect). The respective numbers ( $\mathrm{n}$ ) within each group are given and the standard deviations are calculated.

FSMP, food for special medical purposes. was examined. However, for all intervention groups only minor to no linear relationships could be observed.

\section{DISCUSSION}

According to Montrastruc, alcohol consumption is associated with increased water excretion $(20 \mathrm{~mL} / \mathrm{g}$ ethanol); thus, alcohol-related dehydration might be postulated as being one of the main reasons for most hangover symptoms. ${ }^{32}$ In our study, we could not show any statistically significant relationship between variations in body water content and alcohol consumption. Our results suggest that alcohol-induced increased fluid excretion does not necessarily lead to a significant dehydration process. On the contrary, this effect might represent a subjective perception of increased water loss. Objectively, an increased intake of fluids simply causes an increased excretion of fluids. Thus, the hypothesis that alcohol-induced dehydration is a cause for the expression of hangover symptoms such as headache cannot be supported. Instead, dehydration is more likely to be excluded as a cause for any hangover symptoms. Alcohol consumption is also believed to interfere with the haemostasis of electrolytes and minerals. However, we showed that the intervention with electrolytes, vitamins and minerals did not lead to any statistically significant improvement of or relief from hangover symptoms. Thus, haemostasis of electrolytes and minerals might be not be significantly affected by alcohol consumption. This strongly supports the findings of Ylikahri $e t a l^{8}$ and Penning $e t a l,{ }^{33}$ who also could not detect any changes in electrolyte haemostasis in relation to alcohol consumption. Any correlation between the amount of consumed alcohol and the relative changes in antioxidant capacity in the skin as published by Darvin $e t$ $a l,{ }^{17}$ and that even one-time alcohol consumption reduces the antioxidant capacity of the skin, could not be proven. Thus, it seems to be clear that hangover symptoms are predominantly caused by alcohol and its metabolites (see Introduction). Thus, the intervention study performed 
Table 5 Changes in water content and antioxidant capacity of the skin

\begin{tabular}{llllll} 
& $\begin{array}{l}\text { FSMP } \\
(\mathbf{n = 6 9 )}\end{array}$ & P value & $\begin{array}{l}\text { Vitamins and } \\
\text { minerals }(\mathbf{n = 7 6 )}\end{array}$ & P value & $\begin{array}{l}\text { Placebo } \\
(\mathbf{n}=69)\end{array}$ \\
\hline$\Delta \mathrm{AnOx1}$ & $97.60 \pm 9.74 \%$ & 0.56 & $98.35 \pm 8.44 \%$ & 0.39 & $95.60 \pm 9.98 \%$ \\
$\Delta \mathrm{AnOx} 2$ & $97.10 \pm 11.0 \%$ & 0.66 & $98.40 \pm 7.3 \%$ & 0.27 & $95.58 \pm 8.71 \%$ \\
$\Delta \mathrm{W} 1$ & $99.92 \pm 1.94 \%$ & 0.26 & $98.94 \pm 1.9 \%$ & 0.62 & $98.17 \pm 6.12 \%$ \\
$\Delta \mathrm{W} 2$ & $99.84 \pm 0.49 \%$ & 0.13 & $99.61 \pm 1.21 \%$ & 0.08 & $100.44 \pm 1.53 \%$ \\
\hline
\end{tabular}

$\triangle \mathrm{AnOx} 1=$ the means of individual differences of the antioxidant level in the skin immediately before and after alcohol consumption. $\triangle \mathrm{AnOx}=$ the means of individual differences in antioxidant levels in the skin immediately before and in the morning after alcohol consumption. $\Delta \mathrm{W} 1=$ the means of individual differences in water content relative to body weight, immediately before and after alcohol consumption. $\Delta \mathrm{W} 2=$ the means of individual differences in water content relative to body weight, immediately before and in the morning after alcohol consumption.

FSMP, food for special medical purposes.

with the FSMP hints at a significant reduction in headache intensities by approximately $34 \%$, nausea by $42 \%$, indifference by $27 \%$, and restlessness by $41 \%$. The intervention group receiving the dietary supplement without the plant extract compounds did not show any statistically significant differences from the placebo group.

Polyphenols from the seeds of Trigonella foenumgraecum lead to increased activity of the enzymes ADH and ALDH in the liver. ${ }^{34}$ Polyphenols from the pulp and husk of Magnifera indica $L$. have been shown to decrease blood plasma alcohol levels in mice by increasing the activity of $\mathrm{ADH}$ and $\mathrm{ALDH} .{ }^{35}$ Flavonoids from Asparagus officinalis can also reduce alcohol toxicity by upregulating the enzymatic activities of $\mathrm{ADH}$ and $\mathrm{ALDH},{ }^{36}$ and the same has been shown in mice for linoleic acid derived from Panax ginseng ${ }^{10}$ and polyphenols from the fruits of Pyrus pyrifolia. ${ }^{37}$ In contrast, the application of an extract of Plectranthus species reduces the activity of ADH and acetylcholinergic activity, which leads to a reduced accumulation of acetaldehyde, since aldehyde dehydrogenase activity is not lowered. ${ }^{38}$ Flavones and phenols from Opuntia ficus indica appear to reduce hangover related symptoms by inhibiting the secretion of inflammatory mediators. ${ }^{28} 39$ Flavones and phenols from the leaves and fruits of Diospyros kaki are shown to contribute to the prevention of alcohol-induced liver damage and reduced fat accumulation in mice by activating the antioxidant system. ${ }^{40}$ For ginkgolide B from the leaves of Ginkgo biloba, neuroprotective properties can be detected. This is justified by the inhibition of seryl and aspartyl protease as well as by the antioxidant activity. ${ }^{41}$ Ginkgolide B inhibits dose-dependent ethanol-induced apoptosis and reduces cellular damage, which might be explained by an increased expression of NADPH oxidases in parallel to an inhibition of ethanol-induced caspase- 3 expression. ${ }^{42}$ As a result of the antioxidant properties of Zingiber officinale extracts, hepatoprotective effects ${ }^{43}$ have been shown in detail, and also seem to protect against histological changes in the liver, ${ }^{44}$ kidneys ${ }^{45}$ and lungs ${ }^{46}$ A number of the latter substances are essential ingredients of the FSMP. Thus, it can be assumed that the effects observed in the context of this study are mainly due to the plant extracts contained therein. The underlying mechanisms remain to be unravelled and surely need further investigation. Finally, this study significantly supports the finding that the haemostasis of electrolytes and minerals inferred by alcohol consumption might not be as strongly affected as believed, as any significant dehydration process due to (moderate) alcohol consumption also could not be observed and thus cannot be corroborated.

Acknowledgements We thank an anonymous proof reader for helpful comments.

Contributors PS and BL designed the study. PS performed execution. Analyses were done by PS and BL. The manuscript was written by BL.

Funding This study was partly supported by a European FSMP manufacturer which provided drinks and supplements. Special funding did not occur because the study was part of a masters thesis.

Competing interests None declared.

Patient consent for publication Not required.

Provenance and peer review Not commissioned; externally peer reviewed.

Data availability statement All data relevant to the study are included in the article or uploaded as supplementary information.

Open access This is an open access article distributed in accordance with the Creative Commons Attribution Non Commercial (CC BY-NC 4.0) license, which permits others to distribute, remix, adapt, build upon this work non-commercially, and license their derivative works on different terms, provided the original work is properly cited, appropriate credit is given, any changes made indicated, and the use is non-commercial. See: http://creativecommons.org/licenses/by-nc/4.0/.

\section{REFERENCES}

1 van Schrojenstein Lantman M, van de Loo AJ, Mackus M, et al. Development of a definition for the alcohol hangover: consumer descriptions and expert consensus. Curr Drug Abuse Rev 2016;9:148-54.

2 Verster JC, Stephens R, Penning R, et al. The Alcohol Hangover Research Group consensus statement on best practice in alcohol hangover research. Curr Drug Abuse Rev 2010;3:116-26.

3 Wiese JG, Shlipak MG, Browner WS. The alcohol hangover. Ann Intern Med 2000;132:897-902.

4 Prat G, Adan A, Sánchez-Turet M. Alcohol hangover: a critical review of explanatory factors. Hum Psychopharmacol 2009;24:259-67.

5 Penning R, McKinney A, Verster JC. Alcohol hangover symptoms and their contribution to the overall hangover severity. Alcohol Alcohol 2012;47:248-52.

6 Haas SL, Feick P, Singer MV. Hangover symptoms after alcohol consumption: epidemiology, risk factors and pathophysiology. Sucht 2006;52:317-26.

7 Slutske WS, Piasecki TM, Hunt-Carter EE. Development and initial validation of the hangover symptoms scale: prevalence and 
correlates of hangover symptoms in college students. Alcohol Clin Exp Res 2003;27:1442-50.

8 Ylikahri RH, Leino T, Huttunen MO, et al. Effects of fructose and glucose on ethanol-induced metabolic changes and on the intensity of alcohol intoxication and hangover. Eur J Clin Invest 1976;6:93-102.

9 Singer M, Batra A, Mann K. Alkohol und Tabak - Grundlagen und Folgeerkrankungen. Stuttgart: Georg Thieme Verlag, 2011: 73-88.

10 Lee DI, Kim ST, Lee DH, et al. Ginsenoside-free molecules from steam-dried ginseng berry promote ethanol metabolism an alternative choice for an alcohol hangover. J Food Sci 2014;79:C1323-30.

11 Meier P, Seitz HK. Age, alcohol metabolism and liver disease. Curr Opin Clin Nutr Metab Care 2008;11:21-6.

12 Deitrich RA, Petersen D, Vasiliou V. Removal of acetaldehyde from the body. In: Chadwick DJ, Goode J, eds. Novartis Foundation symposium. New York: John Wiley, 2007: 23-40.

13 Zakhari S. Alcohol metabolism and epigenetics changes. Alcohol Res 2013;35:6-16.

14 Zimatkin SM, Pronko SP, Vasiliou V, et al. Enzymatic mechanisms of ethanol oxidation in the brain. Alcohol Clin Exp Res 2006;30:1500-5.

15 Brandt M, Garlapati V, Oelze M, et al. NOX2 amplifies acetaldehydemediated cardiomyocyte mitochondrial dysfunction in alcoholic cardiomyopathy. Sci Rep 2016;6:32554.

16 Lieber CS. Role of oxidative stress and antioxidant therapy in alcoholic and nonalcoholic liver diseases. Adv Pharmacol;997:601-28.

17 Darvin ME, Sterry W, Lademann J, et al. Alcohol consumption decreases the protection efficiency of the antioxidant network and increases the risk of sunburn in human skin. Skin Pharmacol Physiol 2013;26:45-51.

18 Pigeolet E, Corbisier P, Houbion A, et al. Glutathione peroxidase, superoxide dismutase, and catalase inactivation by peroxides and oxygen derived free radicals. Mech Ageing Dev 1990;51:283-97.

19 Bindu MP, Sreekant KS, Annamali PT, et al. Effect of S-allile cysteine sulphoxide on lipid metabolism and free radical scavenges in alcoho fed rats. Curr Sci 2002;82:628-31.

20 Das SK, Vasudevan DM. Effect of ethanol on liver antioxidant defense systems: a dose dependent study. Indian J Clin Biochem 2005;20:80-4.

21 Karadayian AG, Bustamante J, Czerniczyniec A, et al. Alcohol hangover induces mitochondrial dysfunction and free radical production in mouse cerebellum. Neuroscience 2015;304:47-59.

22 Stephens R, Ling J, Heffernan TM, et al. A review of the literature on the cognitive effects of alcohol hangover. Alcohol Alcohol 2008;43:163-70.

23 Rohsenow DJ, Howland J. The role of beverage congeners in hangover and other residual effects of alcohol intoxication: a review. Curr Drug Abuse Rev 2010;3:76-9.

24 Pittler $\mathrm{MH}$, Verster JC, Ernst E. Interventions for preventing or treating alcohol hangover: systematic review of randomised controlled trials. BMJ 2005;331:1515-8.

25 Rohsenow DJ, Howland J, Minsky SJ, et al. The acute hangover scale: a new measure of immediate hangover symptoms. Addict Behav 2007;32:1314-20.

26 Jadad AR, Moore RA, Carroll D, et al. Assessing the quality of reports of randomized clinical trials: is blinding necessary? Control Clin Trials 1996;17:1-12.

27 Pittler MH, White AR, Stevinson C, et al. Effectiveness of artichoke extract in preventing alcohol-induced hangovers: a randomized controlled trial. CMAJ 2003;169:1269-73.
28 Wiese J, McPherson S, Odden MC, et al. Effect of Opuntia ficus indica on symptoms of the alcohol hangover. Arch Intern Med 2004;164:1334-40

29 Schulz KF, Grimes DA. Reihe Epidemiologi 6: Generierung von Randomisierungslisten in randomisierten Studien: Zufall, nicht Auswahl. Lancet 2002;359:515-9.

30 Schulz K, Altman D, Moher D. Consort 2010: Aktualisierte Leitlinie für Berichte randomisierter Studien im Parallelgruppen-Design. Dtsch med Wochenschr 2011;136:e26-23.

31 Widmark EMP. Principles and applications of medicolegal alcohol determination (Baselt RC, trans). Davis: Biomedical Publications, 1981.

32 Montrastruc P. Lálcool exager la soif. HCEIA Informations 1986;4:41-2.

33 Penning $R$, van Nuland M, Fliervoet LAL, et al. The pathology of alcohol hangover. Curr Drug Abuse Rev 2010;3:68-75.

34 Kaviarasan S, Anuradha CV. Fenugreek (Trigonella foenum graecum) seed polyphenols protect liver from alcohol toxicity: a role on hepatic detoxification system and apoptosis. Pharmazie 2007;62:299-304.

$35 \mathrm{Kim}$ S-H, K Cho S, Min T-S, et al. Ameliorating effects of mango (Mangifera indica L.) fruit on plasma ethanol level in a mouse model assessed with $\mathrm{H}-\mathrm{NMR}$ based metabolic profiling. J Clin Biochem Nutr 2011;48:214-21.

36 Kim B-Y, Cui Z-G, Lee S-R, et al. Effects of Asparagus officinalis extracts on liver cell toxicity and ethanol metabolism. J Food Sci 2009;74:H204-8.

37 Dembitsky VM, Poovarodom S, Leontowicz $\mathrm{H}$, et al. The multiple nutrition properties of some exotic fruits: biological activity and active metabolites. Food Res Int 2011;44:1671-701.

38 Brito E, Gomes E, Falé PL, et al. Bioactivities of decoctions from Plectranthus species related to their traditional use on the treatment of digestive problems and alcohol intoxication. J Ethnopharmacol 2018;220:147-54.

39 Wiese JG, Mcpherson S, Shlipak MG. The effect of Opuntia ficus indica on the severity of the alcohol hangover. J Gen Intern Med 2002; $17: 134$

40 Song YS, Kim MJ, Ma J. Protective effects of persimmon leaf and fruit extracts against acute alcohol-induced hepatotoxicity. Prev Nutr Food Sci 2007;12:202-8.

41 Brunetti L, Orlando G, Menghini L, et al. Ginkgo biloba leaf extract reverses amyloid beta-peptide-induced isoprostane production in rat brain in vitro. Planta Med 2006;72:1296-9.

42 Zhang C, Tian X, Luo Y, et al. Ginkgolide B attenuates ethanolinduced neurotoxicity through regulating NADPH oxidases. Toxicology 2011;287:124-30.

43 Nwozo SO, Osunmadewa DA, Oyinloye BE. Anti-fatty liver effects of oils from Zingiber officinale and Curcuma longa on ethanol-induced fatty liver in rats. J Integr Med 2014;12:59-65.

44 Shirpoor A, Rezaei F, Fard AA, et al. Ginger extract protects rat's kidneys against oxidative damage after chronic ethanol administration. Biomed Pharmacother 2016;84:698-704.

45 Shanmugam KR, Ramakrishna $\mathrm{CH}$, Mallikarjuna $\mathrm{K}$, et al. Protective effect of ginger against alcohol-induced renal damage and antioxidant enzymes in male albino rats. Indian J Exp Biol 2010;48:143-9.

46 Shirpoor A, Gharalari FH, Rasmi Y, et al. Ginger extract attenuates ethanol-induced pulmonary histological changes and oxidative stress in rats. J Biomed Res 2017;31:521-7. 